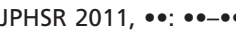

(C) 2011 The Authors

JPHSR @ 2011 Royal

Pharmaceutical Society

Received September 16, 2010

Accepted November 10, 2010

DOI

10.1111/j.1759-8893.2010.00034.x

ISSN $1759-8885$
Correspondence: Francesca

Wirth, Department of Pharmacy,

University of Malta, Msida, MSD 2080, Malta.

E-mail:

francesca.wirth@um.edu.mt

\section{Consumer perception of the community pharmacist and community pharmacy services in Malta}

\author{
Francesca Wirth, Francesca Tabone, Lilian M Azzopardi, \\ Marise Gauci, Maurice Zarb-Adami and Anthony Serracino-Inglott
}

Department of Pharmacy, University of Malta, Msida, Malta

\begin{abstract}
Objectives We aimed to determine the perception of Maltese consumers of the community pharmacist and of the services offered from community pharmacies.

Method A self-administered questionnaire was developed and psychometrically evaluated. Fifty community pharmacies were chosen by stratified random sampling and the questionnaire was distributed to 500 consumers, 10 from each pharmacy, selected by convenience sampling. Descriptive statistics were undertaken.
\end{abstract}

Key findings The majority of the consumers were very or fairly satisfied with various pharmacist characteristics, such as pharmacist efficiency when dealing with requests (95\%), provision of instructions on how to take medications (94\%), pharmacist discretion (91\%), professional pharmacist-consumer relationship (90\%), provision of explanations on how medications work (86\%) and pharmacist knowledge and ability to answer questions (81\%). They were least satisfied with the privacy in the pharmacy (69\%). Consumers were in favour of the evolution of pharmacist professional services, namely the community pharmacist liaising with primary and secondary care-based physicians (91\%), provision of diagnostic testing $(87 \%)$ and extended opening hours $(83 \%)$.

Conclusions Maltese consumers have a positive overall perception of community pharmacists and of the services offered from community pharmacies. They were in favour of the development of extended professional services.

Keywords community pharmacist; community pharmacy practice; consumer; perception; satisfaction

\section{Introduction}

Consumer satisfaction is an integral component of the quality of primary health care. Determining consumer perception of patient-centred services provides a perspective through which standards of care can be identified, enabling the pharmacist's role to be judged for overall quality and satisfaction for improvements to be made accordingly. ${ }^{[1,2]}$ Increasing consumer knowledge about the contribution of the community pharmacist in health care can help to make consumers more aware of how community pharmacists can use their drug and disease knowledge in the improvement of care. ${ }^{[3]}$

At the same time, community pharmacists in primary care face difficult choices in balancing the commercial and professional aspects of their profession. ${ }^{[4]}$ In most countries, community pharmacy is run on a profit basis and is not subsidised by the state; therefore for community pharmacists to survive, profit is a must. The dual commercial/professional role of the community pharmacist is a subject of continual discussion. Community pharmacists taking a business-oriented approach and placing profit before the consumer's needs will perceive giving advice and explanations on the correct use of medications as a waste of time and as not directly involving additional financial remuneration, and will therefore devote less time to patients. ${ }^{[5]}$

It is the community pharmacist's professional responsibility to appreciate the factors governing the safe and effective use of medicines, question patients about their symptoms and related factors, recommend the most appropriate products and liaise with physicians and other healthcare professionals. ${ }^{[6-8]}$ A pharmacist convinced that a particular product could jeopardise a consumer's health, has the responsibility of refusing to dispense the product. Such a refusal, supported by a well-founded and rational explanation offered in a language the consumer can understand, is a success of the professional aspect of community 
pharmacy over the business aspect. ${ }^{[6]}$ The projection by community pharmacists of a patient-centred service will support positive consumer perception which should in turn provide financial stability in the long term.

\section{Community pharmacy in Malta}

Malta is an independent country and a member of the European Union. With a total population of around 414000 and 209 community pharmacies, Malta has a pharmacy to population ratio of approximately 1:1980, one of the highest across the European Union. ${ }^{[9]}$ All prescription-only and nonprescription medicines can only be purchased from a community pharmacy. Community pharmacies in Malta are privately owned, run on a profit basis and are not subsidised by the state. The Malta Medicines Authority stipulates that community pharmacies in Malta must open Monday to Saturday from 09:00 to $12: 00$ and from 16:00 to $19: 00$ and on Sunday and public holidays from 09:00 to 12:00 according to a roster.

Data from a local study carried out in 2009 shows that for principal employment, community pharmacy employs the largest sector of the pharmacist workforce in Malta (30\%). Pharmacists are also employed in medical representation (16\%), hospital and clinical pharmacy $(9 \%)$, industrial pharmacy $(8 \%)$, regulatory affairs $(4 \%)$ and pharmacy administration $(3 \%)$. The remaining pharmacist workforce are teaching $(5 \%)$, retired $(10 \%)$, residing abroad $(3 \%)$ or not practising pharmacy $(12 \%) .{ }^{[10]}$

The aim of this study was to determine the perception of Maltese consumers of the community pharmacist and the level of satisfaction with current pharmacy services offered from Maltese community pharmacies.

\section{Method}

\section{Choosing the sample}

The sampling frame consisted of all community pharmacies in Malta. These were divided according to the five districts stipulated by the Maltese National Statistics Office and tabulated alphabetically in a Microsoft Excel spreadsheet. Each pharmacy was assigned a number consecutively as listed on the Excel spreadsheet, starting from number 1 for each district. Ten community pharmacies were selected from each district by stratified random sampling using a table of random numbers. Ten consumers were recruited by convenience sampling from each of the 50 pharmacies, providing a sample of 500 consumers.

\section{Questionnaire details}

A self-administered questionnaire was developed. Various literature sources were reviewed to develop the questionnaire. ${ }^{[1,5,11-17]}$ The questionnaire addressed the following topics: consumer contact with pharmacies, consumer satisfaction with services provided, perception of the pharmacist, seeking advice and the treatment of minor ailments, extended role of the community pharmacist and consumer perception regarding payment for such services.

The questionnaire was available both in the English and Maltese languages and consisted of 14 structured questions. The questionnaire consisted of close-ended questions, exclud- ing questions for demographic data and a comments section. For questions intended to measure consumers' attitudes and opinions, respondents were presented with statements and asked to agree or disagree using a five-point Likert-type scale. For questions dealing with services offered from a community pharmacy, the consumers could either select one or more than one response as applicable.

\section{Psychometric evaluation}

Face and content validity, reliability, applicability and practicality testing of the questionnaire were carried out. Validation of the questionnaire was carried out by a group discussion with 10 persons: two hospital pharmacists, two community pharmacists, two general practitioners, two pharmacy students and two consumers. The validation panel members were asked to go through the questionnaire and suggest any amendments. A discussion was held afterwards, led by the investigator (FW). This was done to establish whether any important information was omitted, whether the layout was clear and easy to follow and to establish whether the questions asked were well understood or required reformatting. Particular attention was focused on instructions.

Test/retest reliability testing was undertaken where 10 consumers were chosen by convenience sampling and asked to fill in the questionnaire at time 0 (Test 1) and a week later (Test 2). A high Cronbach's alpha correlation coefficient of 0.90 was obtained, rendering the questionnaire reliable. The average time taken to fill in the questionnaire was $6 \mathrm{~min}$ (range 3-12 $\mathrm{min}$ ).

\section{Data collection}

The 50 community pharmacies, which were randomly selected, were personally visited by the investigator and informed consent was given to carry out the study. Subsequently a total of 50 visits were carried out, each of 3-h duration, where the investigator handed out the questionnaire to participants. These visits took place on different days of the week, mostly between 16:00 and 19:00. Although this method was rather time-consuming, it proved to be simple, cheap and achieved a very high response rate. The questionnaire was given to 10 consumers selected by convenience sampling. Consumers visiting the pharmacy to either purchase products or to visit the physician's pharmacy clinic were approached, informed about the nature of the study and invited to participate. They were advised that their enrolment was voluntary, their care would not be affected by their choice not to participate and their answers would be confidential. Those consumers who were not able to fill in the questionnaire at that time were given a stamped selfaddressed envelope to return the questionnaire by mail; however, this was rarely the case.

\section{Statistical analysis}

Once all the completed questionnaires were collected they were coded in Microsoft Excel and descriptive statistics were calculated using Biomedical Data Processing Software (BMDP). 


\section{Results}

\section{Consumer demographic information}

The total study population consisted of 500 consumers. Both sexes were well represented: $52 \%$ female and $48 \%$ male. Most of the consumers $(41 \%)$ were educated to graduate level. The age distribution of the consumers was predominantly in the 36 - to 45 -year age group (24\%), with a mean and median age of 40 and 38 years respectively (range 18-84 years). Most of the consumers occupied managerial, administrative or executive positions $(29 \%)$, followed by professionals (example lawyers, accountants and teachers) and technical workers (21\%), clerks and housewives (each 16\%).

\section{Consumer patterns for visiting the community pharmacy}

Some $48 \%$ of consumers visited the community pharmacy monthly or less frequently, $32 \%$ visited two to three times a month, $14 \%$ went weekly and only $6 \%$ visited the pharmacy more than once a week. Most consumers (67\%) frequently visited the same community pharmacy, $22 \%$ always visited the same community pharmacy and $11 \%$ rarely visited the same community pharmacy.

The two most common reasons for visiting a community pharmacy were to purchase medicines prescribed by a physician $(90 \%)$ and to purchase non-prescription medicines $(65 \%)$. Other reasons included: to purchase cosmetics and toiletries (40\%), to ask the pharmacist for advice (25\%) and to purchase baby products $(5 \%)$.

Most consumers chose to visit a particular community pharmacy as it was close to their home or work place $(80 \%)$, followed by $44 \%$ who sought pharmacist sympathy and friendliness when choosing a community pharmacy. Other determining factors included: the availability of a wide range of products (38\%), provision of a quick and efficient service $(29 \%)$, pharmacy loyalty (18\%) and the layout and appearance of the pharmacy $(17 \%)$.

\section{Satisfaction with pharmacist characteristics}

The majority of consumers had a very good perception of the community pharmacist and were very or fairly satisfied with various pharmacist characteristics, namely pharmacist efficiency when dealing with their requests $(95 \%)$, provision of instructions on how to take medications (94\%), language used by the pharmacist $(93 \%)$, discretion $(91 \%)$, professional pharmacist-consumer relationship $(90 \%)$, provision of explanations of how medications work (86\%), pharmacist knowledge and ability to answer questions $(81 \%)$ and pharmacist interest in their health $(77 \%)$. The consumers were least satisfied with the privacy in the pharmacy $(69 \%)$ and the amount of time the pharmacist spends with them (73\%) (Figure 1).

\section{Business versus the professional aspect}

The majority of the consumers $(56 \%)$ regarded pharmacists as both business people and healthcare professionals; $35 \%$ considered pharmacists to be primarily healthcare professionals and $9 \%$ perceived them as primarily business-oriented people.

When asked about payment for community pharmacists' services, the majority of the consumers were not willing to pay for advice given when purchasing a non-prescription

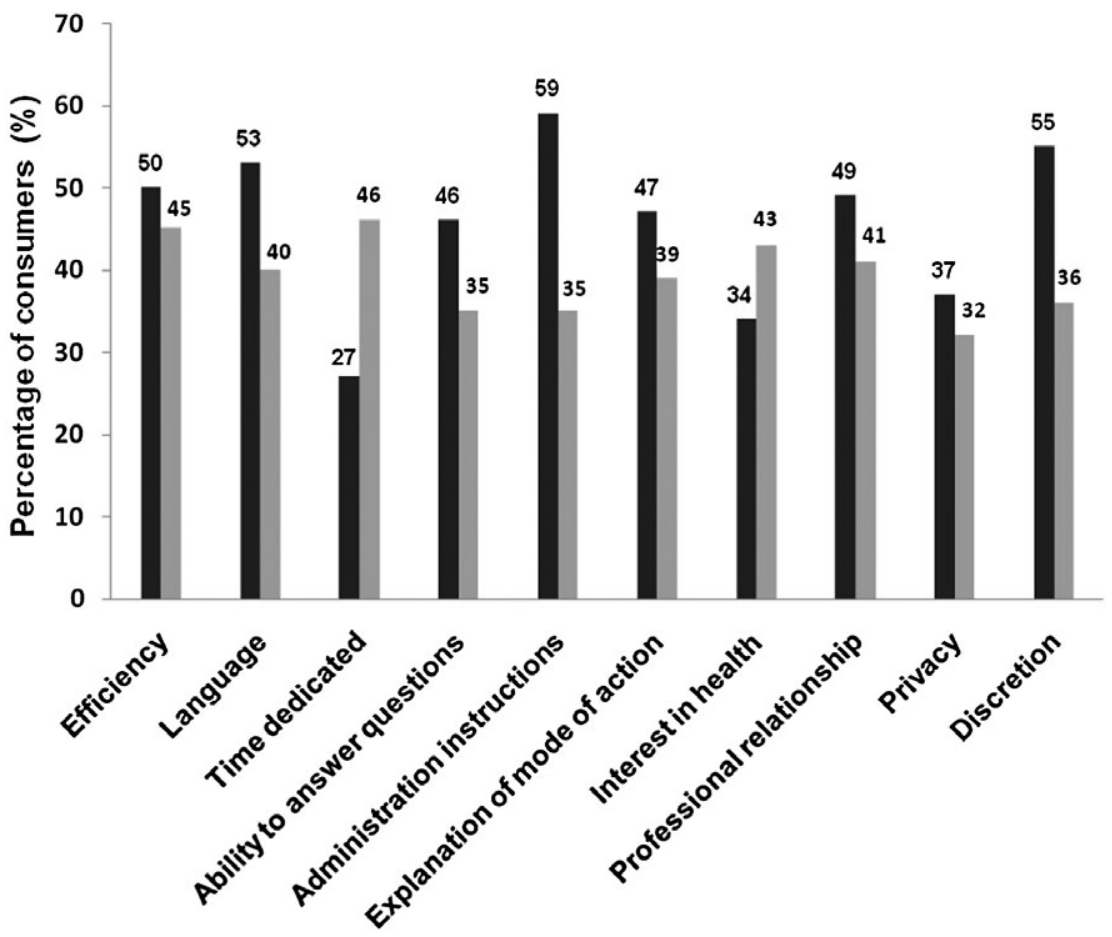

Characteristic

Figure 1 Satisfaction with pharmacist characteristics $(n=500)$.

Very satisfied; ( $\square$ ) Fairly satisfied. 
product $(80 \%)$, for advice given when purchasing a prescription product $(83 \%)$ and for general advice given about any presented complaints $(72 \%)$.

\section{Purchasing non-prescription medication and health advice}

The majority of the consumers $(75 \%)$ confirmed that they would rely on the community pharmacist's choice when purchasing a non-prescription medication. When looking for health advice, only $11 \%$ of the consumers would first consult the community pharmacist, with $76 \%$ first consulting the physician. Other sources of advice were from a family member or friend $(10 \%)$ and the internet $(4 \%)$.

The majority of the consumers $(80 \%)$ would seek advice from a community pharmacist when their condition was not serious enough to visit a physician, $15 \%$ would ask the community pharmacist for advice when they had no time to wait for a physician's appointment, $13 \%$ found it easier to talk to a community pharmacist and $6 \%$ of the consumers opted for the community pharmacist's advice since no fee is charged. Only $13 \%$ of consumers would never ask a community pharmacist for advice.

\section{Treatment of minor ailments}

Thirteen ailments were presented from which the consumers had to choose whether they would consult the community pharmacist or physician or self-treat. The majority of consumers would primarily seek advice from a community pharmacist for cough (44\%) and constipation (38\%). Many consumers would also consult the community pharmacist for acne, spots and rashes, colds and flu, indigestion and diarrhoea (Figure 2).

\section{Perception of community pharmacist extended roles}

Consumers were in favour of the evolution of various professional services, namely the community pharmacist liaising with primary and secondary care-based physicians (91\%), provision of diagnostic testing $(87 \%)$, extended pharmacy opening hours $(83 \%)$ and presence of a private consultation area in the pharmacy $(80 \%)$. The consumers were less in favour of the collaboration of community pharmacists and physicians in the management of chronic conditions (68\%), community pharmacist accessibility outside pharmacy

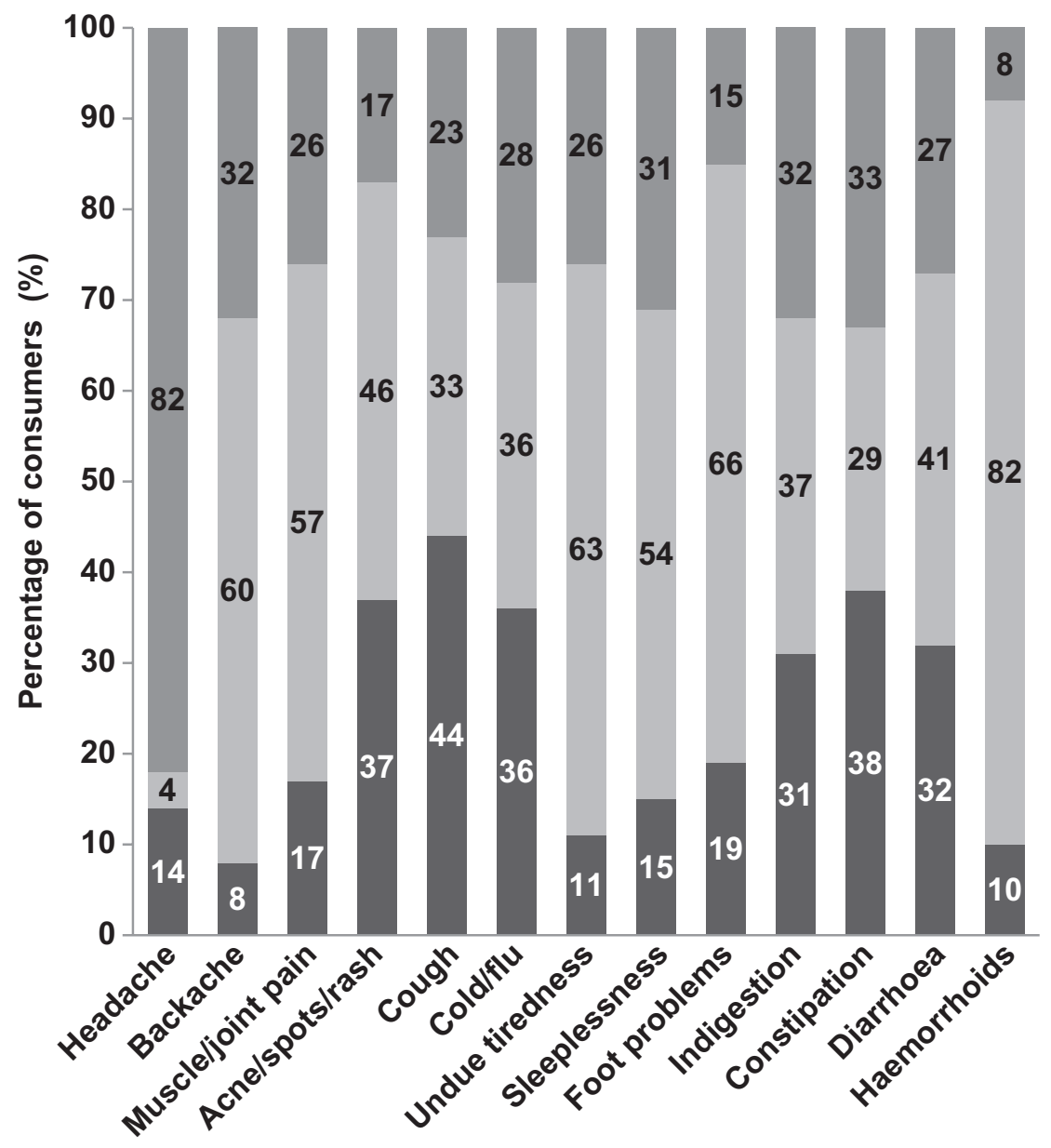

Minor ailment

Figure 2 Treatment of minor ailments $(n=500)$. ( $\square$ ) Self-treat; ( $\square$ ); Doctor; ( $\square$ ) Pharmacist. 
Table 1 Community pharmacist extended roles $(n=500)$

\begin{tabular}{|c|c|c|c|c|c|}
\hline & $\begin{array}{c}\text { Very } \\
\text { important }\end{array}$ & $\begin{array}{c}\text { Fairly } \\
\text { important }\end{array}$ & $\begin{array}{l}\text { Neither important } \\
\text { nor unimportant }\end{array}$ & $\begin{array}{l}\text { Not very } \\
\text { important }\end{array}$ & $\begin{array}{c}\text { Not } \\
\text { important }\end{array}$ \\
\hline Longer pharmacy opening hours & $56 \%$ & $27 \%$ & $10 \%$ & $4 \%$ & $3 \%$ \\
\hline Pharmacist accessibility outside pharmacy opening hours & $39 \%$ & $28 \%$ & $18 \%$ & $9 \%$ & $6 \%$ \\
\hline Private area for consultation & $46 \%$ & $34 \%$ & $10 \%$ & $7 \%$ & $3 \%$ \\
\hline Diagnostic testing (urinalysis, blood pressure, blood glucose monitoring) & $57 \%$ & $30 \%$ & $9 \%$ & $2 \%$ & $2 \%$ \\
\hline Liaison with primary and secondary care-based physicians & $62 \%$ & $29 \%$ & $7 \%$ & $2 \%$ & $0 \%$ \\
\hline Management of chronic conditions (asthma, hypertension, diabetes) & $33 \%$ & $35 \%$ & $23 \%$ & $7 \%$ & $2 \%$ \\
\hline Pharmacist prescribing & $15 \%$ & $32 \%$ & $21 \%$ & $22 \%$ & $10 \%$ \\
\hline
\end{tabular}

opening hours $(67 \%)$ and community pharmacist prescribing (47\%) (Table 1).

\section{Discussion}

This study indicates that Maltese consumers have a positive overall perception of the community pharmacist and the services provided in community pharmacies.

Patient satisfaction is an important measure of how well services are provided. ${ }^{[18]}$ The majority of consumers in this study were very or fairly satisfied with a number of pharmacist characteristics. Similar findings were obtained in the USA,${ }^{[1,19]}$ the UK ${ }^{[15]}$ and the Netherlands. ${ }^{[17]}$ The majority of consumers in this study frequently or always visited the same community pharmacy, indicating a high pharmacy patronage. The outcome from this data is encouraging since the high degree of loyalty to a particular community pharmacy could transmit satisfaction with the services being offered. This finding is supported by studies carried out in the $\mathrm{UK}^{[14,15]}$ and in Canada. ${ }^{[20]}$

Studies from the $\mathrm{UK}^{[21,22]}$ and South Africa ${ }^{[23]}$ report similar reasons to those identified in this study for consumers visiting a particular community pharmacy namely, proximity to home or work and pharmacist friendliness and sympathy. The most common reason for visiting a community pharmacy identified in the current study was to purchase medicines prescribed by a physician, which is comparable to results from Bell et al. ${ }^{[15]}$ in the UK.

The majority of consumers in the current study considered pharmacists to be both business people and healthcare professionals and this is supported by a study carried out by Hargie et $a l{ }^{[14]}$ in the UK. Yet, the majority of Maltese consumers in this study were not willing to pay for any pharmacist advice. On the contrary, from a study carried out among Canadian consumers, willingness to pay and reimbursement levels were shown to be moving in a positive direction. ${ }^{[20]}$

The advisory role of the community pharmacist with regards to minor ailments was accepted by Maltese consumers since the majority of the consumers stated that they would seek advice from a community pharmacist for a number of minor ailments and when their condition was not serious enough to visit a physician. Maltese consumers also confirmed that they would rely on the community pharmacist's choice when purchasing a non-prescription medicine.

Similarly, in the UK, the community pharmacy was seen as the most appropriate place for the treatment of minor illness. ${ }^{[24]}$ However, in two separate studies carried out by the
Welsh School of Pharmacy, ${ }^{[25,26]}$ only a small percentage of consumers stated that they would ask a pharmacist for advice regarding minor ailments, as they believed that pharmacists do not know enough about their individual health. Again in Scotland, it was reported that less than $10 \%$ of a sample of the general public considered the pharmacist to be the "first person for advice on health problems' ${ }^{[27]}$ In Canada, pharmacists and physicians were considered equally as the 'go-to' resources for information about a patient's health. ${ }^{[20]}$

The consumers in this study were least satisfied with privacy in the pharmacy and considered having a private consultation area in the pharmacy as important. Similar complaints against lack of privacy in community pharmacies have been reported in the Netherlands ${ }^{[17]}$ and the UK. ${ }^{[28]}$ The incorporation of private consultation rooms in community pharmacies has been supported in the UK and should be considered as an asset for newly established pharmacies or renovated premises. ${ }^{[14,16,29]}$

Another service development of which consumers in this study were in favour were longer pharmacy opening hours and community pharmacist accessibility outside the pharmacy opening hours. In a study conducted in the UK it was concluded that it may be worth considering telephone help lines, pharmacist domiciliary visits and longer or more varied opening hours to cater for consumer needs and hence extend the professional aspect of community pharmacy. ${ }^{[30]}$

The other areas reported by Maltese consumers for the evolution of community pharmacy professional services were collaboration with physicians in the management of chronic conditions and provision of diagnostic testing. ${ }^{[16]}$

\section{Limitations}

One limitation to this study is that since consumers were selected from within a pharmacy setting, it is possible that only those consumers who regularly visited pharmacies and had a good overall perception of the pharmacist were included in the study, leading to possible bias. One could consider distributing the questionnaires to consumers recruited from public areas and social events. An improvement to the study could be to document the reasons why consumers who completed the questionnaires were visiting the pharmacy; whether to purchase medications from the pharmacist or to visit physicians in the pharmacy clinic.

\section{Conclusion}

Maltese consumers have a positive overall perception of community pharmacists and of the services offered from commu- 
nity pharmacies that is comparable to most studies in Europe and the USA. The study indicates consumer preferences for the evolution of community pharmacist professional services, namely in collaborative care practice, diagnostic testing and extended opening hours.

\section{Declarations}

\section{Conflict of interest}

The Author(s) declare(s) that they have no conflict of interest to disclose.

\section{Funding}

This research received no specific grant from any funding agency in the public, commercial or not-for-profit sectors.

\section{Acknowledgements}

The authors acknowledge the assistance of pharmacists Ms Tanya Debrincat and Ms Sylvana Magrin Sammut in the development of the questionnaire and Professor Anton Buhagiar, Department of Mathematics, Faculty of Science, University of Malta, with statistical analysis.

\section{References}

1. Larson LN et al. Patient satisfaction with pharmaceutical care; update of a validated instrument. J Am Pharm Assoc 2002; 42: 44-50.

2. Krska $\mathbf{J}$ et al. Frequency of counseling on prescription medicines in community pharmacy. Int J Pharm Pract 1995; 3: 178-185.

3. Chewning B, Schommer JC. Increasing clients' knowledge of community pharmacists' roles. Pharm Res 1996; 13: 12991304.

4. D'Arcy PF et al. Role of the general practice pharmacist in primary health care. Pharm J 1980; 224: 539-542.

5. Morrow $\mathrm{N}$ et al. Consumer perceptions of and attitudes to the advice-giving role of community pharmacists. Pharm J 1993; 251: 25-27.

6. Pray WS. The pharmacists as a self-care advisor. J Am Pharm Assoc 1996; 36: 329-334.

7. Zillich AJ et al. Utility of a questionnaire to measure physicianpharmacist collaborative relationships. J Am Pharm Assoc 2006; 46: 453-458.

8. McDermott D et al. General practitioners' attitude to additional services by community pharmacists. Pharm J 1997; 259: R39.

9. Wuliji T. FIP Global Pharmacy Workforce Report. The Hague: International Pharmaceutical Federation, 2009.

10. Hili S. The Maltese directory of pharmacists. Msida, Malta: University of Malta, 2009 (dissertation).
11. Worley MM, Schommer JC. Pharmacist-patient relationships: factors influencing quality and commitment. J Soc Adm Pharm 1999; 16: 157-173.

12. Barnett CW et al. Patient-guided counseling in the community pharmacy setting. J Am Pharm Assoc 2000; 40: 765-772.

13. Krska J, Kennedy E. Expectations and experiences of customers purchasing over-the-counter medicines in pharmacies in the north of Scotland. Pharm J 1996; 256: 354-356.

14. Hargie $\mathrm{O}$ et al. Consumer perceptions of and attitudes to community pharmacy services. Pharm J 1992; 249: 688-691.

15. Bell HM et al. Societal perspectives on the role of the community pharmacist and community-based pharmaceutical services. J Soc Adm Pharm 2000; 17: 119-128.

16. Iversen $\mathrm{L}$ et al. Attitudes of the general public to the expanding role of community pharmacists: a pilot study. Fam Pract 2001; 18: 534-536.

17. Pronk MCM et al. Evaluation of patient opinions in a pharmacy: level intervention study. Int J Pharm Pract 2003; 11: 143-151.

18. Kukukarslan S, Schommer JC. Patients' expectations and their satisfaction with pharmacy services. J Am Pharm Assoc 2002; 42: 489-496.

19. Ried LD et al. Patients' satisfaction and their perception of the pharmacist. J Am Pharm Assoc 1999; 39: 835-842.

20. Ratiopharm. The Ratiopharm CFP Report on Pharmacy Services: Consumers' Perception of Pharmacy. Canada: Ratiopharm; 2004. www.ratiopharm.ca/pdf/cfp_eng.pdf (accessed 19 August 2010).

21. Smith FJ. Factors important to clients when seeking the advice of a pharmacist. Pharm J 1990; 244: 692-693.

22. Anderson C. Health promotion by community pharmacists: consumer's views. Int J Pharm Pract 1998; 6: 2-12.

23. Bornman S et al. Public perception of community pharmacists in South Africa: a preliminary study. Health SA Gesondheid 2006; 11: $27-40$.

24. Hassell K et al. A pathway to the GP: the pharmaceutical 'consultation' as a first port of call in primary health care. Fam Pract 1997; 14: 498-502.

25. John DN, Evans SW. Who would the public ask for advice on selected symptoms? Pharm J 1997; 259: R41.

26. John DN et al. Why don't consumers ask community pharmacists for advice on minor ailments? Pharm J 1997; 259: R38.

27. Vallis J. Users' views and expectations of community pharmacists in a Scottish commuter town. Pharm J 1997; 258: 457-460.

28. Hirst JE et al. Analysis of focus group discussion on privacy in community pharmacies. Pharm J 1999; 263: R38-R39.

29. Buisson J. How to make space for a consultation area in your community pharmacy. Pharm J 2005; 275: 689-691.

30. Hassell $\mathrm{K}$ et al. A review of factors that influence the use of community pharmacies as a primary health care resource. Int $J$ Pharm Pract 1999; 7: 51-59. 